\title{
Suicide pacts in a district of Sri Lanka between year 2001 and 2014
}

\author{
Senanayake SMHMK ${ }^{1 *}$
}

\section{Introduction}

Suicide pact is an agreed plan between two or more individuals to commit suicide [1]. The plan may be to die together, or separately and closely timed [2]. It is a rare phenomenon.

\section{Findings of Cases}

During the thirteen years service in northwestern and north central provinces in two provincial general hospitals as the in charge medico-legal consultant for a district only two incidents had been come across out of 10200 postmortem examinations. First case is
56 and 54 years old married couple committed suicide by ingestion of cyanide due to large financial debt in Kurunegala district. Both went to a famous church and then went in to jungle near to sea and ingested cyanide.

Second case is hanging of living together couple after one week of new life in Anuradhapura district. Forty years old male was unmarried. Thirty six years old female was married and having one child. The female wanted that seven (7) years old child but ex-husband had refused to hand over the child to mother. She could not live with the new husband without her child and could not wait till divorce case is completed (Fig.1). In both cases suicidal notes were available.

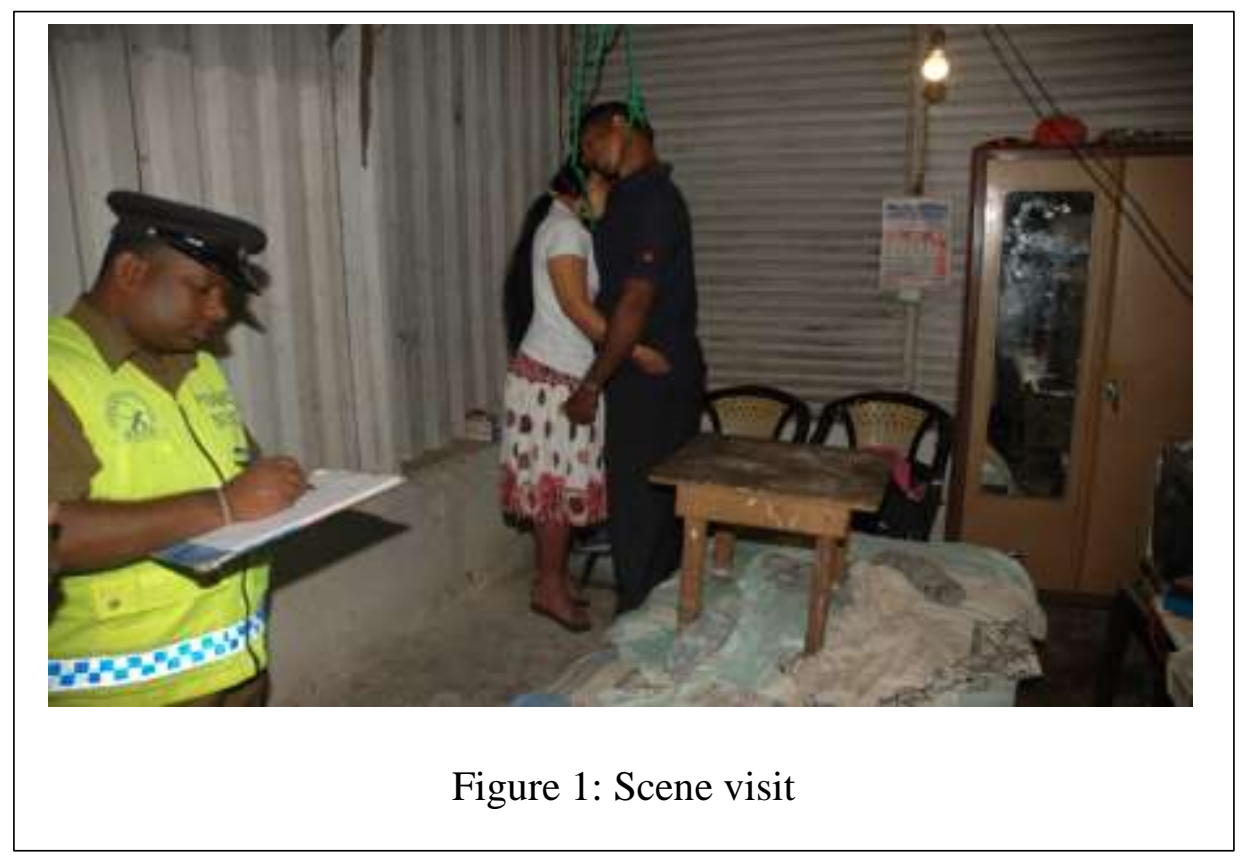

${ }^{1}$ Consultant Judicial Medical Officer, Teaching Hospital Anuradhapura

\section{Discussion}

*Corresponding author: Senanayake SMHMK, Tele: 0094718195569, e-mail address: dilruksena62@yahoo.co.uk

Suicide pacts were usually reported in married couples, blood relatives and lovers. Survivors had shown that one member had been depressed [3]. In above two cases also one member had a very strong reason for depression- large debt and loss of the child. Through internet websites rarely strangers have got together and had committed suicide in more numbers [4]. Causes of suicide pacts were found as 
mental disorders, avoiding of loss partner from ill health, euthanasia and thwarted love [5].

Victims of suicide pacts differed significantly from single suicides on several variables: tendency to use guns, leave suicidal notes, have blood alcohol levels, be older, be less depressed and to commit suicide in the morning hours [6].

The world health organization revealed on $5^{\text {th }}$ of September 2014 that instances of suicide were most prevalent in Guyana, North Korea, South Korea, Sri Lanka, Lithuania, Suriname, Mozambique and Nepal. Even though suicides are common in Sri Lanka among unmarried young people and old people, suicide pacts are very rare. During the 13 year service of the author only two suicide pacts were encountered out of 10200 postmortem examinations.

\section{Conclusion}

Even though suicide is common in Sri Lanka among old persons and unmarried young persons, suicidal pacts are very rare. One incident is seen after several years in a district i.e. one incident per about 5000 postmortem examinations. They were seen in married, middle aged couples.

\section{References}

1. Sikary AK, Swain R, Dhaka S, Gupta SK, Yadav A. Jumping Together: A Fatal Suicide Pact. Journal of Forensic Science. 2016 Sep 19. doi: 10.1111/15564029.13193. [Epub ahead of print]

2. Vidanapathirana M, Sanjeewa HKR, Niroshani PAGK, Amararatne RRGS. Can this be suicidal pact or dyadic deaths? 12th Indo-Pacific Congress on Legal Medicine and Forensic Sciences of the Indo-Pacific Association of Law, Medicine and Science (INPALMS) 2016, in Bali Indonesia.

3. Milton Rosenbaum. Crime and Punishment- the suicide pact. Archives of General Psychiatry.1983;40(9):979-982

4. Suicide pacts and the internet. Editorial BMJ 2004;329:1298

5. Martin Brown, Brain Barraclough. Partners in life and death; the suicide pact in England and Wales 1988-1992. Psychological medicine,29(6)1999,1299-1306

6. Fishbain, David A at all. A controlled study of suicide pacts. Journal of Clinical Psychiatry. 45(4), 1984,154-157 